\title{
Laser hair removal: No training required?
}

Previously published at www.cmaj.ca

$\infty \quad$ See related news story, page 755

I magine licensing a car but not the driver or, in medical terms, licensing an endoscope but not the physician who uses it. That, in effect, is what Canada's governments are doing with laser machines used for hair removal. And, like most machines and instruments for which a licence is required for operation, the laser machine is a powerful device with potential to harm.

Usually painless and effective, laser hair removal has become the method of choice for many women and men. Sure, it is expensive, does not work on all types of hair or skin, and may require several visits for treatment, but the results are superior to conventional methods of hair removal. Because of the popularity of laser hair removal, owning a laser machine is akin to having a licence to print money.

Medical offices, spas, beauty salons - even the smallest strip malls - offer laser hair removal. In Canada, no licence is required to operate the machine, and training is usually provided by the manufacturer. Only the machine itself is licensed by Health Canada. Therefore, anyone, trained or not, can legally operate a laser machine for hair removal in Canada.

Is this lack of regulation a problem? Although controlled trials of laser hair removal have shown that severe adverse effects are uncommon, ${ }^{1}$ there have been reports of burns, pigmentary changes, scarring, reactivation of herpes viruses and even paradoxical hypertrichosis. ${ }^{2,3}$ Ocular complications, such as uveitis and iritis, have occurred when the eyes have not been shielded adequately. ${ }^{3}$

Many of these adverse effects can be minimized with appropriate selection of clients, use of the correct wavelength for a person's skin and hair type, cooling of the skin during treatment, eye protection, and appropriate pre- and post-treatment care. ${ }^{4}$ Although the literature generally does not indicate whether the adverse effects occurred when the laser hair removal was performed by trained or untrained providers, surely some kind of mandatory training or licensing should be required to operate a laser device for hair removal.

In the United Kingdom, the Care Standards Act 2000 requires that operators of laser or intense light pulse systems be registered with the Care Quality Commission; failure to do so is a criminal offence. In the United States, the Food and Drug Administration requires that laser machines be marketed as prescription devices; they are therefore subject to state controls that ensure they are used by or under the supervision of specific licensed practitioners.

In contrast, Health Canada recommends that anyone considering laser hair removal "be sure that the person who will operate the laser device has the training and experience needed to perform the procedure safely and effectively." 5

Health Canada also suggests that the client ask the operator for references and check that the laser device has been licensed by Health Canada for hair removal. So without any specific knowledge about techniques and equipment for laser hair removal, the client is required to judge the fitness of the operator and the suitability of the laser machine.

For other types of cosmetic laser treatments (e.g., removal of pigmented lesions), Health Canada encourages clients to seek the services of a licensed medical professional with specialized training in laser procedures. ${ }^{4}$ Other health-related use of laser machines (e.g., for eye surgery) is generally regulated by provincial or territorial governments or colleges of physicians and surgeons.

To allow untrained staff to operate laser devices with such potential for harm is unreasonable. Canadians should insist that Health Canada, our national regulator of medical devices, set minimum training standards for operators of lasers used for hair removal. To protect the public, provinces and territories should license both clinics and operators and establish standardized training programs for both novice and experienced operators of laser hair removal devices.

Because of the wide range of people involved in this growing multibillion-dollar industry, training and licensing should be flexible and allow all who are interested, health professionals and others, to develop expertise with these devices and techniques.

In the right hands, laser hair removal can be safe and effective. Let's make sure those hands are trained.

\section{Diane Kelsall MD MEd \\ Deputy Editor, Clinical Practice \\ CMAJ}

With the editorial advisory team: Ken Flegel MDCM MSc, Paul C. Hébert MD MHSc, Noni MacDonald MD MSc, Matthew B. Stanbrook MD PhD and Joan Ramsay BA

Competing interests: See www.cmaj.ca/misc/edboard.shtml

CMAJ 2010. DOI:10.1503/cmaj.100475

\section{REFERENCES}

1. Haedersdal M, Wulf HC. Evidence-based review of hair removal using lasers and light sources. J Eur Acad Dermatol Venereol 2006;20:9-20.

2. Lepselter J, Elman M. Biological and clinical aspects in laser hair removal. J Dermatolog Treat 2004;15:72-83

3. Goldberg DJ. Laser- and light-based hair removal: an update. Expert Rev Med Devices 2007:4:253-60.

4. Liew SH. Laser hair removal: guidelines for management. Am J Clin Dermatol 2002;3:107-15.

5. It's your health: cosmetic laser treatments. Ottawa (ON): Health Canada; 2004 Available: www.hc-sc.gc.ca/hl-vs/alt_formats/pacrb-dgapcr/pdf/iyh-vsv/med/lasereng.pdf (accessed 2010 Mar. 17). 